tions and the modification of landscapes by glaciation. No other work so conveniently and appreciatively presents such a range and depth of fully digested and appropriate information on these topics.

There has, of course, been an ever increasing volume of publications by geomorphologists, mostly geographers, in these fields since the book was published in 1947, but this has added little real significance to their description and virtually nothing to their understanding. The book thereforo remains entirely relevant.

B. C. KING
"Imperfection in Computer Music", the fascinating subject of the musical value of departing from the "inhuman" sound of steady, periodic stimuli, by introducing perturbations such as vibrato. Again, a recorded illustration is given.

The computer is demonstrated to be a most powerful tool for producing musical sounds; this book is an extremely good description of those powers and potential, and is recommended to all those who are interested in the development which is exciting so many musical minds at the moment.

R. P. Wrlliams

\title{
MUSICAL COMPUTERS
}

Music by Computers

Edited by Heinz von Foerster and James W. Beauchamp. Pp. xviii + 139. (Wilcy: London and New York, June 1969.) $140 s$.

$\mathrm{By}$ now it is evident that computer music has come to stay. In the United States it is well established and this state of affairs will surely obtain soon in Europe and in particular Britain. Several installations of one type or another are being brought into existence in this country and recently the British Society for Electronic Music has been formed. Although there is a fair amount of literature on the subject, it has, in general, been confined to "small-time" publication and to research papers scattered in various journals. But here, in this beautifully produced book, we have a broad survey of the subject by several authors, all eminent in one aspect or another of the fiold. One hundred and thirty-nine pages at 140 shillings might, at first sight, seem rather a large sum to pay, but the book does include four 7-inch records of remarkably good quality. The records complement the book and provide an intriguing and varied programme.

The book is a collection of papers based on contributions to the Joint Computer Conference held in the autumn of 1966. Professor Heinz von Foerster organized the "Computers in Music" section of the conference and he writes a short but fascinating introductory article on "Sounds and Musie" which summarizes the essence of the relationship between the character of musical scunds and that of the human auditory system. After this tho book is divided into three sections, the first dealing with the fundamentals of generating music by computers, the second with the problems of composing and scoring and the third with the aesthetics of computer music.

The most substantial and detailed paper is by $J$. W. Beauchamp concerning the problems of analysis of tones produced by conventional musical instruments and subsequent synthesis by a computer. By these means ono is able to correlate subjective judgments on musical sounds with some objective ingredient in thern. A paper by Arthur Roberts then gives an account of current computer programs for music synthesis, such as MUSIC IV and ORPHEUS; records of two pieces illustrate the techniques.

The second section of the book, dealing with composition, opens with an article by Lejaren Hiller in which are described programs involving subroutines and randomnumber sequences which can generate a piece of music to an outline specification by the composer. Continuing on this theme is an article by M. V. Mathews and L. Rosler on the problem of providing scores of music to be generated by the computer. Incorporated with this is an intriguing record of "Rhythm Developments" where a simple tune "The British Grenadiers" is subtly changed as time goes on to the tune "Johnny Comes Marching Home". The transition from $\mathrm{F}$ ' major in $2 / 4$ time to $\mathrm{E}$ minor in $6 / 8$ time is quite uncanny, and, after we hear the latter melody, it is changed back again to the first one.

The final section is devoted to aestheties and consists of three articles ending with one by Gerald Strang on

\section{Correspondence}

\section{Molecular Biology at Spetsai}

SIR,--We, the undersigned, are a group of non-Greek scientists of the Fourth NATO Advanced Study Institute of Molecular Biology, held in July 1969 in Spetsai, Greece. Many of our colleagues refused to attend this meeting because of their objection to the military government now ruling Greece. Because of their position, we wish to inform them, and the private citizens of our countries of origin, of our attitude towards this meeting.

First, we believe that the holding of a scientific meeting of this sort in Greece is a distinct advantage to scientists of that country. To refuse to attend facilitates the isolation of the Greek intellectual community, thereby cutting them off from the free interchange of information and ideas. For these reasons we believe that such meetings should continue to be held in Grece. We bolieve that they are of value in demonstrating the international nature of science and the desirability of a free and full exchange of views. It is with these belicfs that we went to Spetsai; our visit in no way reflects approval of the Greek government.

Second, attendance at such meetings should be dependent upon certain assurances being given concerning the financial and political independence of the meeting and the unrestricted admission of participants. In this case, Dr Francis Crick, the chairman of the Organizing Committee of the Study Institute, sought the assurance by the Greek government that it did not intend to make any political propaganda in connexion with the meeting. Its representative stated that the Greek government appreciated the strictly scientific nature of the meeting. Dr Crick also obtained the assurance of the freedom of admission for students from Eastern European countries resulting in the granting of visas to them for the duration of the course.

Finally, we believe that the exact sources of finance for such meetings should be declared in advance. We consider it important that this school should in no way depend financially upon a government which we consider to be oppressive. We feel strongly that the attitude of such of our home countries as, singly and collectively, support the Greek military government is deplorable.

Yours faithfully,

$\begin{array}{ll}\text { H. Andersen } & \text { P. Henson } \\ \text { P. K. Avner } & \text { M. Herzberg } \\ \text { P. M. Bayley } & \text { W. Kabsch } \\ \text { C. Bordier } & \text { D. Kettlewell } \\ \text { S. Chang } & \text { M. A. Koblinsky } \\ \text { R. Cotter } & \text { T. A. Krulwich } \\ \text { R. M. Dittgen } & \text { D. B. Malcolm } \\ \text { S. Dolfni } & \text { D. Paulin } \\ \text { A. Fantoni } & \text { J. M. Pesando } \\ \text { P. Gilbert } & \text { G. Pieczenik } \\ & \text { G. Rosenbaum }\end{array}$

